\title{
Facing Crisis: Saving a Company via Cultural Transformation
}

\author{
Pim Soonsawad (Corresponding author) \\ Department of International Business, National Taiwan University \\ No.1, Sec. 4, Roosevelt Rd., Taipei City 106, Taiwan \\ Tel: 886-2-33664991 2, 886-2-2363-1066 \# 11170 \\ E-mail: pimka17@gmail.com
}

\begin{abstract}
Crisis may require an organization to transform itself; however, transformation may not necessarily help the organization overcome the crisis. Two crises occurred in Taiwan that forced many businesses to change their operating style. The earthquake on September 21, 1999 and the outbreak of SARS in 2003 forced organizations to change. These two calamities exposed companies to a series of challenges which often required creativity and change to overcome. This research is a case study of how a Taiwanese company overcame the challenges caused by these crises, transforming itself from a customer-led business to a market-oriented business. Specifically, we extend Lewin's planned change model to investigate the storytelling and organizational communication styles used in different stages of this company's transformation. The findings reveal that a company can actively respond to crisis thereby providing guidelines for organizations facing catastrophe and chaos.
\end{abstract}

Keywords: Crisis, Organizational transformation, Cultural artifacts, Market orientation, Case study

\section{Introduction}

On September 21, 1999, the most severe earthquake in Taiwan's recorded history, 7.3 on the Richter scale, struck the central region of the island, killing 2,494 people, injuring 13,799, destroying 51,392 houses completely and damaging 104,833 houses severely. More than 310,000 residents were displaced. Total damage was estimated at 11.5 billion US dollars, including losses from collapsed buildings, shattered transportation infrastructure, and diminished industrial production due to a two-week power outage (Directorate-General of Budget, Accounting and Statistics, 2000). The increase in the gross domestic product (GDP) fell from a projected $6.72 \%$ to $4.89 \%$ after the earthquake; meanwhile, the annual consumer price index (CPI) growth rate dropped from a projected $1.7 \%$ to $0.2 \%$. These figures indicate that not only did consumer's purchasing power decline but also consumer willingness to consume weakened (Directorate-General of Budget, Accounting and Statistics, 2009). The focus of consumer expenditure changed as well. With the mindset of living in the moment, people temporarily shifted from a long-term perspective to a short-term orientation; spending more on luxuries rather than long-term investment such as continued education (Pavia \& Mason, 2004).

While still recovering from the earthquake, a catastrophic epidemic, the Severe Acute Respiratory Syndrome (SARS), attacked Taiwan in the spring of 2003. During the SARS outbreak, consumer confidence severely declined reducing spending in Asian economies between $\$ 11$ billion and $\$ 18$ billion (General Accounting Office, 2004). The SARS outbreak impacted the service sector including those companies in travel, tourism, retail sales and continuing education, especially hard (Cheng \& Wen, 2004).

One of the challenges that companies faced was that many Taiwanese started to avoid going to public places and became more isolated emotionally and socially. This resulted in a major reduction in private consumption spending, forcing many service firms to confront bankruptcy; some went out of business, others struggled to survive, while some thrived. The outstanding businesses in the last category are of particular interest. Understanding how these companies endured the crises, engaged in organizational change and adopted different business philosophies can provide valuable insight to business leaders, who may face future crises. This research uses a case study investigating the organizational transformation of one exemplary Taiwanese company to improve our understanding of how to successfully manage organizational change. "TutorABC", an extracurricular education company not only survived but became a market leader in a new business domain - the live e-learning industry

TutorABC initiated a thorough organizational transformation to respond to the crises. This transformation involved three stages, matching Lewin's Planned Change Model, from a brick-and-mortar business to a dot-com business. To add clarity Lewin's original stages are divided into two parts, with six short-term objectives as follows (1) Awareness of the need for change; (2) Conformity toward the new goal; (3) Adaptiveness to the new route, (4) Compliance with the new 
rules; (5) Consolidation into unison; and (6) Elevation beyond status quo (AC-AC-CE).

The analysis combines this organizational change model with marketing and organizational culture analysis. Interestingly each of the six stages shows unique characteristics in the use of cultural artifacts and each of the three main stages of transformation also correspond to a particular marketing strategy of the company. In addition, the company developed its IT capabilities and expanded its use of network communications to gain the man advantages offered by this business model.

Organizational behavior literature on both organizational transformation and cultural artifacts will be reviewed, before discussing research methodology, site selection and data collection. Thirdly, an analysis of how TutorABC Company evolved to overcome the crisis, followed by a discussion on the theoretical significance and managerial contributions of this evolution. Finally, a discussion of how these findings might be beneficial in terms of inspiring organizational leaders to consider how the tool of storytelling might be used and we will offer suggestions for future research.

\section{Literature Review}

\subsection{Organizational Change}

To develop an understanding of the different facets of an organizational transformation, we first review literature on organizational transformation, mainly Lewin's planned change model. A second important factor is organizational culture (Johnson, 1990; Pascale, Millemann, \& Gioja, 1997). An organizational culture is typically reflected in the organization's cultural artifacts, such as stories and communication styles (Dirskill \& Brenton, 2005 \& Martin, Feldman, Hatch \& Sitkin., 1983; Conrad, 1990), which will be reviewed in the second part of this section. Organizational Transformation

Organizational change theory is well developed and well researched; however even though more complicated models exist; the foundation of organizational change theory remains Lewin's Planned Change Model (Armenakis \& Bedeian, 1999). Lewin (1951) theorized that a successful organizational transformation involves three stages: unfreezing, moving, and refreezing. The unfreezing stage, advocates of organizational change will unfreeze a quasi-stationary equilibrium, a fragile balance constructed by driving forces and restraining forces, in order to initiate the organizational transformation (Burnes, 2004; Lewin, 1951; Wilson, 1992). At the moving stage, the organization utilizes internal resources to conduct experiments regarding business operations and then evaluates the results iteratively to explore viable transformation routes. Once the organization identifies the most appropriate route, it crystallizes (refreezes) group behaviors to ensure movement along the calibrated direction.

Beverland and Lindgreen (2007), Armenakis \& Bedeian (1999) Day (1999), Gebhardt, Carpenter and Sherry (2006), and Homburg \& Pflesser (2000) all used Lewin's model to study organizational change. In fact Beverland and Lindgreen (2007) regard Lewin's model as the most relevant change model for radical planned change. The previously noted research shows that Lewin's model could be utilized to study an organizational transformation with the following characteristics: The transformation is unexpected, radical, goal oriented and longitudinal. The transformation must be necessitated by unexpected events such as crises, which require a massive and comprehensive process of organizational transformation to counter the crisis. The change will be guided by a goal proposed by organizational leaders at the initial stage and the nature of transformation is relatively slow and needs a longer period of time to complete. These four characteristics can be found in this case. Hence, this research similarly adopts Lewin's model as its framework.

\subsection{Cultural Artifacts}

Researchers of organizational transformation have demonstrated their interest in cultural transformation in recent years (Gebhardt, Carpenter \& Sherry, 2006; Harris \& Mossholder, 1996; Homburg \& Pflesser, 2000). Since the concept of organizational culture is an essential factor in organizational transformation, (Burke, 1995; Cummings \& Worley, 2005; Johnson, 1990; Pascale, Millemann \& Gioja, 1997), senior executives must make use of cultural artifacts to successfully achieve cultural transformation because the artifacts are powerful tools in creating change (Cummings \& Worley, 2005; Higgins \& McAllaster, 2004). Schein (1992) defined cultural artifacts as the visible symbols of the deeper, underlying culture such as stories, rites, myths, . Studies of cultural artifacts may rely on one element, such as stories (Brown, 1990; Meyer, 1992). However this article examines two cultural artifacts, storytelling and organizational communication styles (Dandridge, Mitroff, \& Joyce, 1980; Trice \& Beyer, 1993). Stories that denote the sequences of events in the history of an organization and storytelling facilitate the dissemination of experiences, morals, perspectives, and beliefs among an organization's members. Storytelling is an effective means of helping organization members accept vital beliefs, such as an organization's vision and mission, more easily (Boyce, 1996; Foster, 2002), which aids in making sense of vague situations, such as a crisis and forming precedents for future actions and decisions (Boje, 1991). Storytelling can serve as a proactive managerial tool since senior management can actively establish links between strategy, culture, and stories in the transformation process to enhance the probability of success (Higgins \& McAllaster, 2004). Observations of an organization's storytelling techniques can assist in understanding a company's reaction to a crisis and its corresponding strategy in a period of change. 
Organizational scholars have shown that organizational communication style, defined as "a collective preference by organization members for certain channels of communication", (Dirskill \& Brenton, 2005, p. 50) is a cultural artifact which is important in studying the organizational change process (Albrecht \& Hall, 1991; Albrecht \& Ropp, 1984; Fairhurst \& Wendt, 1993; Rogers, 1995; Van de Ven, Angle \& Poole, 2000). Communication channels can be non-verbal (facial and body language), oral, written, and online multi-media. Each communication style plays a different role in conveying information. Organization executives often communicate complex messages through several channels at once. Our research will show how communication style affected the implementation of the organizational change.

\section{Research Method}

The purpose of qualitative research is to develop an understanding of individuals and events in their natural state, taking into account the relevant context (Lincoln \& Guba, 1985; Leedy \& Ormrod, 2005; Kostere, Koster \& Percy, 2008; Creswell, 2008). Gerring (2004) suggests that case study is best defined as an intensive study of a single unit with an aim to generalize across a larger set of units. Case studies are often used to answer the how and the why questions (Yin, 1994). The case study approach allows for the in-depth examination of a phenomenon which is present in context, such as is the case of TutorABC in which longitudinal and dynamic characteristics are prominent (Leedy \& Ormrod, 2005; Kostere, Koster \& Percy, 2008; Creswell, 2008, Eisenhardt, 1989). Leedy and Ormrod (2005), Kostere, Kostere and Percy (2008) and Creswell (2008) suggest that extensive data should be gathered on the subject of the study to provide as much detail as possible.

\subsection{Site Selection}

Four criteria were set for choosing the firm to study how artifacts facilitate transformation. The company needed to have been affected by the earthquake and the SARS outbreak. Second, the company had to be in the service industry, which suffered from those crises, most. Third, the company should be relatively small as small firms are more flexible in reconfiguring their internal resources to face a crisis. Finally, the company needed to have recently entered the refreezing stage as this would provide more relevant data

Tutor ABC was chosen as it met all of the criteria. Established in September 1998(Note 1), TutorABC was a brick-and-mortar extracurricular educational service (an English learning institution) company with less than 20 employees; which transformed itself in three years to the industry leader in online instruction with more than 400 employees.

\subsection{Data Collection}

The longitudinal-procedural method was used for this research, collecting data from April 2008 to April 2009. Using a simple longitudinal model of change, the firm was examined at three stages: initiating change, changing, and consolidating reforms. After explaining the purpose to the management team they were supportive and permitted the author to engage in participant observation over a period of one year and we spent eight months interviewing and collecting historical documents that focused on the key players in the transformation of TutorABC.

This research employed unstructured and semi-structured interviewing. Using unstructured and semi-structured interviews with questions focused on gaining a descriptive history of the motivation for change, the pressure for and against change, top management's influence, problems that emerged in the course of transformation, and how IT developments related to communication styles.

We conducted interviews with a wide range of employees to gain a broad perspective on the changes that took place. Interview questions were open-ended and participants were encouraged to speak freely. The author attended the interviews, one asking questions and one taking notes. The interviews were recorded on an MP3 recorder and then translated into English.

Interviewing stopped when saturation occurred, that is, when extra interviews began to yield few novel insights (Strauss \& Corbin, 1998). The final sample consisted of nine interviewees, with in-depth interviews totaling 28 recorded hours (Table 1). The full transcript, including information from each interview and secondary sources, totaled 178 pages (155 for formal interviews, 23 pages for field notes).

To organize data from field notes and interview transcripts, data reduction techniques such as coding, labeling, and abstracting were used (Strauss \& Corbin, 1998). Data was manually coded after the completion of each interview and analyzed to identify themes relevant to the research. To ensure the accuracy and reliability of the coding, the raw data was separately coded by two people and the results compared. Any areas where the coding did not agree were removed from further consideration. Throughout the interviewing stage theory on organizational change and organizational culture was referenced to ground interpretations as they emerged. Other documentation considered in the analysis included the company website, Intranet Management System (IMS) data, internal company e-mail, archival research, training course material, employee regulations, advertising document reviews, meeting minutes, and video recordings 
both of CEO speeches and of annual activities observed during non-participant and participant observation. These extra steps serve to ensure triangulation (Strauss \& Corbin, 1998; Yin, 1994) and to supply extra sources to help understand discrepancies among informants and allow additional perspectives on key events and issues (Miles \& Huberman, 1994).

\section{Results}

TutorABC was like most small-sized firms just getting started; the top executives worked very closely with their employees and encouraged members to accept certain values and rules (Denning, 2004). Chris, the R\&D manager, said:

'Early in the beginning of the company, the CEO together with employees distributed pamphlets to customers on the street from early in the morning until 8 p.m., regularly. . The company's rule was to be punctual. On one occasion the CEO was late by a few minutes and he was rebuked by the founder...Since then, everybody followed the rule.'

This story emphasizes the commitment to customer satisfaction; even the CEO was handing out brochures. A second theme is that the enforcement of rules at that early stage mainly relied on an oral style of organizational communication. Profits were suddenly cut by the most devastating earthquake in Taiwan's modern history. The company's classrooms were ruined, public infrastructure was destroyed, and transportation became a major difficulty for both teachers and customers. Adjusting to the setback, the company invested in the development of the computerized automatic assessment system, resulting in the creation of the Dynamic Course Generation System (DCGS) in 2002, a system utilized to assign customized study materials to students. Meanwhile, TutorABC kept working on other ways to serve their customers, but a concrete plan for organizational transformation was not formulated until the SARS outbreak.

The emergence of SARS affected both current and potential customers of TutorABC. Since SARS spread through the air, many existing customers became reluctant to go to classrooms. The situation negatively impacted the bottom-line of the company, giving top executives a strong sense of urgency and a motivation to evolve their business. One possible solution generated by the top executives was to establish e-commerce. Mark, the founder of TutorABC, explained his determination to work in this direction:

'The earthquake gave us a big warning sign that we could not solely depend on a traditional brick-and-mortar business model. We were thinking about some other possibilities...The SARS outbreak gave us the motivation to quickly enact our ideas or else fail.'

We can see that the earthquake and SARS drove TutorABC to conduct a transformation toward a goal set by top managers. During the following three years, the company went through a massive organizational transformation process. By 2006, TutorABC successfully operated an online business and reshaped consumers' learning experience into what the company claimed in its slogan: 'English at anytime, anywhere.' In the next section, we will examine the transformation of TutorABC in the context of Lewin's three-stage view.

\subsection{UNFREEZING STAGE}

\subsubsection{Storytelling}

Awareness of the need for change. The story below illustrates creating awareness and convincing employees through storytelling. According to Chris, the R\&D manager:

'When SARS first broke out, the CEO was quick to ask our IT team...to accelerate research on on-line products and to evaluate new possibilities within the market. He said: You know, once there was a hotshot Japanese company, NOVA or something. When times were good, it moved into an expensive part of town where the rent was very high. However, when bad times came, it could not keep up with the rent. Well... in the end that company closed down... Why? It failed to realize that it might need a change."

The SARS crisis forced the TutorABC to re-examine its core business as top-management realized the weaknesses of the current business model. Matthews \& Scott (1995) argued that the awareness of environmental uncertainty of top executives is unquestionably an influential antecedent to strategic planning processes in small businesses. The above story displays the factors Lewin (1947) identified, the awareness occurring in the unfreezing stage is cognitive exposure to the change idea, diagnosis of the problem, and the engendering of solutions.

Conformity toward the new goal. During the unfreezing stage, top managers are driven not only to create awareness of the need for change but also to produce a consensus in favor of change. Chris, the R\&D manager, said:

'We all felt that the idea of operating a live e-learning center would be impossible, but our founder insisted. He continually encouraged us to keep going and to develop the online system. I remember once in a meeting he told managers, "don't think that live e-learning is impossible. No one can invent products very smoothly.

The key factor in this stage is conformity, defined by Kosslyn and Rosenberg (2004, p. 703) as 'a change of belief or actions in order to follow a group's norms.' In this case, a number of employees preferred working at a traditional classroom business because they feared the uncertainty of creating a new business model. As Armenakis \& Bedeian (1999) wrote, an employee's established skills may become invalid when an organizational change is initiated. To 
overcome these restraining forces, top executives used storytelling to bring employees into alignment with the organizational goal "to build a new business of live e-learning based on TutorABC's traditional classroom model," and thereby reached the consensus for change. The employees could then accept the new goal and consequently the desired transformation commenced.

\subsubsection{Organizational Communication: Oral Style}

Oral communication is often the primary method during the unfreezing stage. Senior managers frequently used teleconferences and meetings which involved a great volume of oral communication. As the CEO explained "oral communication helps to reduce fear about crises."

Oral communication allows people to quickly comprehend complicated phenomena they have never encountered, exchange opinions immediately, and generate alternatives and solutions in a timely fashion. Such characteristics facilitate organizational members' awareness of the need for change and their conformity toward the new goal of the organization.

\subsection{MOVING STAGE}

\subsubsection{Storytelling}

Adaptiveness to the new route; as the product prototype was being developed in 2004, TutorABC entered the moving stage. In order to initiate the live e-learning business model, TutorABC constructed a new department responsible for online services, internal infrastructure and systems were changed, such as the institution of a live e-learning demo room. Despite its effort to nurture the new business, TutorABC still faced several challenges in marketing. Mary, general manager, said:

The CEO often said that one day someone would appreciate our products. At those times, his confidence gave employees hope. John continually shared stories with the employees. He said, "Don't be frustrated. The reason why our service is very hard to sell is not a quality issue but rather an adaptiveness issue."

Inspiration is a key factor in achieving employee buy-in, and the employees started to modify their skills to promote the company's novel online service. As evidenced by the new working schedule from 8:30 a.m. to 10:30 p.m.

Adaptiveness is most often described as how well a person can fit into their environment (Gitterman, 1995; Fraser, 1997; German \& Gitterman, 1987) at TutorABC adaptiveness occurred during the moving stage, at which point employees are responsible for recognizing the agenda and taking action to put these decisions in practice (Gebhardt, Carpenter \& Sherry, 2006). Previous authors noted that result-oriented, information-sharing, developmental, and employee-centered cultures are supposed to enhance adaptiveness (Denison, 1984; Kanter, 1983; Walton, 1985).

Compliance with the new rule. In addition to asking employees to enhance their capability to adapt to organizational change, TutorABC offered employees incentives or rewards when they performed well and advanced the company's new goals. According to Chris, The CEO said, "I promise that when TutorABC makes an IPO [Initial Public Offering] on the stock exchange someday, all of you can join the ESOP [Employee Stock Ownership Plan]." However if employees did not follow the new program they would be punished.

On the other hand, even those who were considered top performers would be punished if their behavior contradicted the company's culture. Mary, the general manager, said:

I remember in 2006, before the product was formally launched, ten employees were fired because they colluded with competitors. Once, the CEO reminded us in a meeting, "You need to be careful with company data, especially with new employees or employees who have not completed the probationary period." After that, the managers were stricter in enforcing the company's new rules; we no longer shared sensitive data with other departments without prior approval.

This story is an example of "compliance," which is defined as "the acceptance of influence in order to gain specific rewards and to avoid punishments' (Klein \& Sorra, 1996, p. 1061). Similarly, Kosslyn and Rosenberg (2004, p. 706), state that compliance is a change in behavior brought about through a direct request rather than by social norms. The company used rewards and punishment to achieve compliance. Compliance accelerates organizational change by complementing the adaptiveness that is fostered in the moving stage. A successful organizational change requires both the members' ability, which is the core of adaptiveness, and their willingness, which is central to compliance.

\subsubsection{Organizational Communication: Written Style}

Unlike the unfreezing stage where the company mainly relied on an oral communication style, in the moving stage it used several different styles. Although oral communication is effective in dealing with emergency situations, the importance of written communication is enhanced in the moving stage. The moving stage involves a complex situation with more employees, more departments, and more complicated tasks (Palvia \& Ghervany, 1989). In this situation, an organization may find itself trapped in conflicts and confusion without written communication. The following quotation describes the communication problems experienced across departments. Chris, the R\&D Manager, said: 
Our colleagues thought we in the $R \& D$ Department just weren't working hard enough and constantly nagged us about their queries... Later, during a meeting, we voiced our grievances, and all participants agreed that our company should start to use a "request form" in order to reduce inter-departmental conflict. This would mean that when other departments submitted a request for a job, they would do so on paper, which was really great for us and for the company too.

Written documents are traceable and can be iteratively reviewed and checked in horizontal communication, thus alleviating interdepartmental conflicts. Moreover, written documents can also serve as supporting materials to oral communication to clarify ambiguities, especially in the case of vertical communication. This function can be observed in the following narrative.

'During the testing phase of our new product [live e-learning], we asked and noted the opinions of customers who participated in a free trial of our products. We then used these written comments to improve our new products.' [Mary, general manager]

We see that top executives used oral and written communication to deliver their messages to organization members because of the benefits of these different styles of communication, which allow for understanding of goals, strategy, and tactics, to supporting cultural change and create a harmonious environment among departments (Somech, Desivilya, \& Lidogoster, 2009), enhancing the company's ability to achieve organizational goals. Through oral and written communication, the employees working together as a team could understand goals, strategy, and tactics, supporting cultural change and creating a harmonious environment among departments. TutorABC recovered from the crisis, emerged from the fiercely competitive traditional classroom market, and sailed through the storm to its next stage.

\subsection{REFREEZING STAGE}

\subsubsection{Storytelling}

Consolidation into Unison. The moving stage ended when the company finished development and launched their new product. TutorABC arrived at the refreezing stage in 2007. Since then, the sales department has added about 200 sales representatives. However, when they interacted with potential customers, they faced a lot of questions that they couldn't respond to immediately. As a result, the company has been continually investing in the integration of production (i.e., course materials), marketing, sales, human resources, and R\&D functions into the Intranet Management System (IMS). The IMS enables each division to locate its own data at any time. When logging on to the IMS, each employee has a password that will allow them a certain level of access to the company's information. This system facilitates the conflux of business intelligence that helps new employees quickly become accustomed to the working procedures of TutorABC. Nancy, a senior specialist of human resources and a former salesperson, told a story to articulate the function of IMS:

'The company gathered top salespeople to work out 3 to 4 sales pitches in response to possible questions and compiled a reference for all the sales representatives. In the end, the IT department compiled those sales pitches and integrated the information into IMS so that everyone could access the information promptly.

Meanwhile, TutorABC unified the goals of the different departments by developing a Key Performance Index (KPI) for each department. One of the original KPIs for the marketing department was based on the number of people who responded to the company's advertisements and left their personal information which caused the marketing staff to get as many names as possible. The more customers lured by the marketing department, the more phone calls the sales department had to make to customers who were not likely to purchase the service. Without properly filtering the customer list, salespeople would waste their time contacting non-target customers, hence lowering their performance, which was measured by the hit rate. Salespeople identified this problem and petitioned for a revision of the KPIs. TutorABC thus redesigned its KPIs by establishing a clearer definition of target customers, which it then used to trim the list compiled by marketing creating congruence of goals of the two departments.

In addition, TutorABC utilized customer satisfaction as one of the inputs to determine employees' compensation, which further consolidated the front-end system (i.e., interface between TutorABC and the customers) and back-end system (i.e., IMS). The IMS and KPI systems work together to maximize the efficiency of all levels of the company. The KPI system defines roles and gives clear goals, while the IMS system provides the information needed to achieve the goals. Adding customer feedback as noted in the story, was the final step in the process.

Elevation beyond status quo. TutorABC not only intends to satisfy customers but also tries to go beyond customer's expectations by offering sympathetic service. Allen, a consultant, recalled a story told by the CEO in a meeting:

'The CEO's secretary would often e-mail us a business-related story or article one week before our regular meetings, so everyone could read it and then discuss their opinions during the meeting. We liked this type of meeting because we really learned a lot from the discussion. One time, the CEO used an example from RBC [Royal Bank of Canada] to teach us. He summarized the RBC story, cited from a Harvard Business Review article:

"The daughter of RBC's president once lost her RBC credit card in the United States, and was told when she contacted 
the local branch that she would have to get the card replaced in Canada. She was very angry and complained of this poor service to her father. The president decided to take action and hired a consulting firm to better understand customer satisfaction... The analysis indicated that there are two kinds of satisfaction: rational satisfaction (i.e., the satisfaction about the number of branches, the diversity of products etc.) and emotional satisfaction (i.e., the service attitudes, amenities, etc.). RBC got a high score on rational satisfaction but a low score on emotional satisfaction.

While rational satisfaction is comparable to hygiene factor, emotional satisfaction is more influential when it comes to repurchasing decisions. So, let's pay attention to customers' emotional satisfaction. Read our customers' opinions. Put yourself in the customer's shoes. Remember! Always put customers first."

Based on this story, he told us that when customers request a refund, the company should be willing to give back 100\% without asking any questions., because we need to respect customers'opinions and complaints at all times. You know, a $100 \%$ refund policy is pretty rare in Taiwan.

Top executives used stories to encourage employees to exceed the customer's expectations, especially with regard to emotional satisfaction. This change in policy raised industry standards; we call this elevation.

In the refreezing stage, the company would like to crystallize group behaviors by elevating employees' attitudes to ensure movement along the calibrated direction. In order to foster the affection of employees, top executives must show charisma (Conger \& Kanungo, 1994). For example, Nancy, the human resources senior specialist, presented one of the founder's e-mails as follows:

'Dear all, being a good citizen is very important in any community. So please offer your help to me and the other departments whenever you feel it is needed. John and I have made a lot of mistakes in the past 10 years. We all do. We just need a good friend to remind us of those mistakes. You should offer your voice and opinions to the other departments or to me, by emails or via the "idea box" on IMS. You may be right, or may be wrong some times. But, you did your job as a good citizen. This is how a good citizen works for this great company. This is also why we ask our customers to give us their feedback after every session. Never give up! All great companies or nations make mistakes. It all depends on how fast they learn and how they handle the mistakes and move on.

The 'good citizen' ideal represents virtuous behaviors that produce positive attitudes in individuals and then lead to an elevation in positive well-being (Fredrickson, 1998; Seligman, 2002; Fineman, 1999). Employees' positive attitudes (e.g., optimism, passion, sympathy, and gratefulness) can lead to positive habits in their organizations (e.g., politeness, generosity, hospitality, and assistance) and then create affection from customers which then feeds back to reinforce positive attitudes. This virtuous cycle produces a higher level of organizational commitment among employees.

\subsubsection{Organizational Communication: Online Network Style}

TutorABC developed a massive intranet and online network to support organizational communication effectively and efficiently; launching a blog which has oral and written communication. The blog allows departments to share information quickly and efficiently, enhancing the company's effectiveness. Traceability and clarity are two major advantages of written communication. Online network communication not only possesses these advantages, but also holds many other merits. Five additional features of new communication technologies represent important advancements for organizations: 1) increased speed; 2) reduction in the costs; 3) rise in communication bandwidth; 4) expanded connectivity; and 5) real time updating (Fulk and Desanctis, 1995).

Apart from the way it improves on written communication, an online network also incorporates the benefits of the oral communication style using multimedia. For example, employees produced a documentary film to introduce the company's history. The story was acted out by the employees and included much comedic content that made it fun. Their enthusiasm for the film was "infectious and elevated everyone's morale," according to Allen. For the purposes of top-down communication, the oral, face-to-face style is still the most powerful approach (Foster, Cebis, Majetles, Mathur, Morgan \& Preuss, 1999), but the online medium can closely replicate it. TutorABC's training program, for example, reaches teachers spread out around the world and their training is all communicated via online networks. The CEO, John said:

\section{'Our teachers' training is based on the Internet; therefore, our instructors have no restrictions.}

The integration of multimedia communication with online networking technologies makes it even easier to convey information, unify opinions between superiors and subordinates, and, in turn, mold a cohesive organization. The consolidation and elevation fostered by the multimedia online network communication style can help sustain organizational change.

Figure 1 depicts a summary of our findings and illustrates the construct of cultural transformation, based on the three stages of Lewin's planned change model, that we abstracted from storytelling and organizational communication styles. 


\section{Discussion}

This study reveals how a company, confronted with unexpected crisis, can engage in organizational transformation to save itself. As objectives differ from stage to stage throughout the transformation process, top managers utilized cultural artifacts, mainly storytelling and organizational communication styles, to convey information, promote innovation, as well as declare organizational value propositions, to ensure a successful transformation.

In the unfreezing stage, top executives need to increase subordinates' awareness of the need for change and create conformity toward a new goal. To achieve these aims, the executives played an active role in describing the future and energizing employees (Cummings \& Worley, 1997) by making liberal use of storytelling to help employees sense the urgency of developing a new business model and further, to depict a vision beyond the present so that employees are more willing to accept the goal and work toward it (Kickul, Lester, \& Finkl, 2002). The senior managers of TutorABC used frequent oral communication to solidify employee's awareness and conformity and to prevent any negative impacts of gossip which can occur in a time of crisis (Cummings \& Worley, 1997). To mitigate this anxiousness, intensive two-way communication by telephone and small panel meetings was deemed to be the most effective method.

TutorABC realized that before the crises it focused on solving customers' immediate problems and not on innovating. The company was a "customer-led" business, as identified by Slater \& Narver $(1998,1999)$. Reacting to customers rather than predicting the future. If a company adheres to this culture, it may hinder long-term expansion. Top executives at TutorABC, however, sensed the problem and started to ponder customers' latent needs, which are often impossible for customers themselves to articulate (Slater \& Narver, 1999). Partially as a result of the two crises, TutorABC identified the need for a safer, more private, and more convenient environment for learning English and this led to the investment in online infrastructure. Meanwhile, they created cultural change by imbuing employees with the concept of a market-oriented business, a model which has the capacity to satisfy the explicit as well as underlying needs of customers (Slater \& Narver, 1998). After creating the will to change in the unfreezing stage, the company then devoted most of its resources to the development of the live e-learning business model in the moving stage. Transforming the company to a "Product-Centric Market-Oriented" business in this stage; that is, the company emphasized experimentation with new products and market development to enlarge customer base.

Hall (1997, p.31) noted that "to influence cultural change, managers must shape organizational beliefs in the appropriate directions. To do this they must intervene in behavior, justifications of behavior, and cultural communications." The moving stage thus involves a kind of cognitive restructuring, requiring change in both attitudes and behaviors (Schein, 1987). Top executives utilize storytelling, including using the company's history, to help organization members adapt to the new plan and comply with the new rules. The organization also realigned rewards as suggested by Gebhardt, Carpenter, and Sherry's (2006) in the institutionalization stage. By announcing planned compensation, top managers influence employees' beliefs and reinforce their new behaviors.

At this stage written communication takes on new importance as different departments need to exchange clear and traceable information (Kein, 1996), helping to clarify each employee's responsibility and performance. TutorABC has achieved the goal of consolidating organizational systems, for example KPI and IMS in the refreezing stage and customer interface so that those systems and structures could be more coherent and comprehensible to organization members (Silince, 1999). To strengthen the effect of consolidation, senior managers used storytelling to elevate employees' attitudes and initiate a virtuous cycle, an ongoing process of self-monitoring and self-renewal (Hall, 1997).

The online network communication system played a key role to leverage the effects of traditional oral and written communication while offering the speed necessary to respond to the market.

Slater \& Narver (1999) state that a successful market-oriented business refers to a company that seeks to understand customers' expressed and latent needs and develops superior solutions to those needs. Alternatively market orientation could be described as having behaviors associated with the generation and dissemination of market intelligence (Kohli \& Jaworski, 1990). TutorABC fits either definition as the company encourages employees to share opinions and market information through the intranet and, currently, such communication is thriving within the company. Tutor ABC gathers customers' feedback and responds them accordingly through the online interface, enhancing business value. Such behaviors are a reflection of the underlying market-oriented culture (Narver \& Slater, 1998).

\section{Conclusion}

Crises cause immense pressure and uncertainty for organizations and organization members. One way for an organization to face a crisis induced by natural disasters is to conduct an organizational transformation. This study borrows Lewin's planned change model to investigate the cultural artifacts (i.e., storytelling and communication styles) of a company that engaged in an organizational transformation in response to the impact of an earthquake and the SARS outbreak. A modified form of Lewin's three-stage framework was useful in capturing the dynamics of the reaction to the impact of crises. Our research proffers several theoretical implications. First, the paper contributes to research in organizational development by analyzing how artifacts can be used to effect an organizational change. Second, 
integrating organizational change theory and market orientation theory enriched the study of organizational transformation and provided a more complete picture of the process. This approach may provide a useful framework for future research. Finally, the six short-term objectives, Awareness, Conformity, Adaptiveness, Compliance, Consolidation, and Elevation (AC-AC-CE) are the essential elements in the process of organizational change and form a valuable six-strep model which is an extension of Lewin's model.

This research also provides several managerial insights. First suggesting organizations to adopt a long-term orientation when they are faced with unexpected crisis, dealing with the crisis itself may not provide the best solution. Secondly, the research shows that the AC-AC-CE six-step model and a market orientation are sufficient for organizational transformation to overcome the crisis. Thirdly, cultural artifacts should be used to foster the transformation, especially storytelling and communication styles.

\subsection{Suggestions for Future Research}

First of all, the source of our data is confined to a particular organizational context. Future research could include a greater diversity of organizational contexts to elaborate on how cultural artifacts are utilized to ensure organizational success. Secondly, future research would do well to analyze an instance of failure to adopt organizational change, which could more colorfully illustrate our result here. Thirdly, this study focuses on two cultural artifacts: storytelling and organizational communication style. We recommend that the degree to which as well as the way in which these two cultural artifacts are acknowledged, perceived, and received by targeted external customers could form the basis for future research.

\section{Note}

Note 1. Prior to 2004, the business was called Columbia Consulting Company. After 2004, coinciding with the launch of the e-learning business, the company used TutorABC as their primary brand name.

\section{References}

Albrecht, T. L., \& Hall, B. (1991). Relational and content differences between elites and outsiders in innovation networks. Human Communication Research, 17(4), 535-561.

Albrecht, T. L., \& Ropp, V. A. (1984). Communicating about innovation in networks of three U.S. organizations. The Journal of Communication, 34(3), 78-91.

Armenakis, A. A., \& Bedeian, A. G. (1999). Organizational change: A review of theory and research in the 1990s. Journal of Management, 25(3), 293-315.

Beverland, M. B., \& Lindgreen, A. (2007). Implementing market orientation in industrial firms: A multiple case study. Industrial Marketing Management, 36(4), 430-442.

Boje, D. M. (1991). The storytelling organization: A study of story performance in an office-supply firm. Administrative Science Quarterly, 36(1), 106-126.

Boyce, M. E. (1996). Organizational story and storytelling: A critical review. Journal of Organizational Change Management, 9(5), 5 .

Burke, W. W. (1995). Organization development: A process of learning and changing (2nd ed.). Reading, MA: Addison-Wesley.

Burnes, B. (2004). Kurt Lewin and the planned approach to change: A re-appraisal. Journal of Management Studies, 41(6), 977-1002.

Cheng, C. Y., \& Wen, C.T. (2004). The social impact of communication technology in SARS outbreak the STS perspective. The 13 International Conference on Management of Technology. Washington, D.C.: IAMOT

Conger, J. A., \& Kanungo, R. N. (1994). Charismatic leadership in organizations: Perceived behavioral attributes and their measurement. Journal of Organizational Behavior, 15(5), 439-452.

Conrad, C. (1990). Strategic organizational communication: An integrated perspective. (2 ${ }^{\text {nd }}$ ed.). TX: Holt, Rinehart and Winston, Inc.

Creswell, J. W. (2008). Educational research: Planning, conducting and evaluating quantitative and qualitative research ( $3^{\text {rd }}$ ed.). Upper Saddle River, NJ: Pearson

Cummings, T. G.., \& Worley, C. G. (2005). Organization Development and Change (8th. ed.). Ohio, US.: South-Western, Thomson Corporation.

Dandridge, T. C., Mitroff, I., \& Joyce, W. F. (1980). Organizational symbolism: A topic to expand organizational analysis. The Academy of Management Review, 5(1), 77-82.

Day, G. S. (1999). Creating a market-driven organization. Sloan Management Review, 41(1), 11-22. 
Denison, D. R. (1984). Bringing corporate culture to the bottom line. Organizational Dynamics, 13(2), 5-22.

Denning, S. (2004). Telling tales. Harvard Business Review, 82(5), 122-129

Directorate-General of Budget, Accounting and Statistics (DGBAS). (2000). Quarterly national economic trends Taiwan area. R.O.C: Executive Yuan.

Directorate-General of Budget, Accounting and Statistics (DGBAS). (2009). Quarterly national economic trends Taiwan area. R.O.C: Executive Yuan.

Dirskill, G. W., \& Brenton, A. L. (2005). Organizational culture in action : A cultural analysis workbook Thousand Oaks, Calif.: Sage Publications.

Eisenhardt, K. M. (1989). Building theories from case study research. The Academy of Management Review, 14(4), 532-550.

Fairhurst, G. T., \& Wendt, R. F. (1993). The gap in total quality: A commentary. Management Communication Quarterly, 6(4), 441-451.

Fineman, S. (1996). Emotion and organizing. In S. Clegg \& C. Hardy (Eds.), Handbook of Organization Studies (pp. 543-564). London: Sage.

Foster, N., Cebis, M., Majetles, S., Mathur, A., Morgan, O., \& Preuss, J. (1999). The role of story-telling in organizational leadership. Leadership \& Organization Development Journal, 20(1), 11-17.

Foster, R. F. (2002). The Irish story: Telling tales and making it up in Ireland. (1st. ed.). New York: Oxford University Press.

Fredrickson, B. L. (1998). What good are positive emotions. Review of General Psychology, 2(3), 300-319.

Fulk, J., \& DeSanctis, G. (1995). Electronic communication and changing organizational forms. Organization Science, 6(4), 337-349.

Gebhardt, G. F., Carpenter, G. S., \& Sherry, J. F. (2006). Creating a market orientation: A longitudinal, multifirm, grounded analysis of cultural transformation. Journal of Marketing, 70(4), 37-55.

General Accounting Office. (2004). Emerging infectious diseases: Asian SARS outbreak challenged international and national responses. Washington, D.C.

Gerring, J. (2004). What is a case study and what is it good for? The American Political Science Review, 98(2), $341-354$.

Hall, A. A. (1997). Tacit culture and change: A model of change constructed from institutional assumptions and beliefs. Virginia Polytechnic Institute and State University, Blacksburg, Virginia.

Harris, S. O., \& Mossholder, K. W. (1996). The affective implications of perceived congruence with culture dimensions during organizational transformation. Journal of Management, 22(4), 527.

Higgins, J. M., \& Mc Allaster, C. (2004). If you want strategic change, don't forget to change your cultural artifacts. Journal of Change Management, 4(1), 63-73.

Homburg, C., \& Pflesser, C. (2000). A multiple-layer model of market-oriented organizational culture: Measurement issues and performance outcomes. Journal of Marketing Research, 37(4), 449-462.

Johnson, G. (1990). Managing strategic change: The role of symbolic action. British Journal of Management, 1(4), 183.

Kanter, R. M. (1983). The change masters: Innovation and entrepreneurship in the American corporation. New York: Simon and Schuster.

Kickul, J., Lester, S. W., \& Finkl, J. (2002). Promise breaking during radical organizational change: do justice interventions make a difference? Journal of Organizational Behavior, 23(4), 469-488.

Klein, K. J., \& Sorra, J. S. (1996). The challenge of innovation implementation. The Academy of Management Review, 21(4), 1055-1080.

Klein, S. M. (1996). A management communication strategy for change. Journal of Organizational Change Management, $9(2), 32$.

Kohli, A. K., \& Jaworski, B. J. (1990). Market orientation: The construct, research propositions, and managerial implications. The Journal of Marketing, 54(2), 1-18.

Kosslyn, S. M., \& Rosenberg, R. S. (2004). Psychology: the brain, the person, the world (2nd. ed.). Boston: Allyn \& Bacon.

Kostere, K., Kostere, S., \& Percy, B. (2008). Qualitative Analysis Parts I - III. Residence Learning Activity Workbook-Track 3. 
Leedy, P. D., \& Ormrod, J. E. (2005). Practical research: Planning and design (8th ed.). Upper Saddle River, NJ: Prentice Hall.

Lewin, K. (1947). Frontiers in group dynamics. Human Relations,1(1), 5-41.

Lewin, K. (1951). Field theory in social science. In D. Cartwright (Ed.). New York: Harper \& Row.

Lincoln, Y. S., \& Guba, E. G. (1985). Naturalistic inquiry. Beverly Hills, CA: Sage.

Martin, J., Feldman, M.S., Hatch, M.J., \& Sitkin. (1983). The uniqueness paradox in organizational stories. Administrative Science Quarterly, 28(3), 438-453.

Matthews, C. H., \& Scott, S. G. (1995). Uncertainty and planning in small and entrepreneurial firms: An empirical assessment. Journal of Small Business Management, 33(4), 34-52.

Miles, M. B., \& Huberman, A. M. (1994). Qualitative data analysis: An expanded sourcebook. Thousand Oaks, CA: Sage.

Narver, J. C., \& Slater, S. F. (1998). Additional thoughts on the measurement of market orientation: A comment on deshpande and farley. Journal of Market-Focused Management, 2(3), 233-236.

Palvia, S., \& Chervany, N.L. (1989). Effect of environmental and process variables on DSS implementation success: evidence from an experimental investigation for the moving stage of change (Lewin-Schein model). Annual Hawaii International Conference. US: System Science

Pascale, R., Millemann, M., \& Gioja, L. (1997). Changing the way we change. Harvard Business Review, 75(6), 126-139.

Pavia, T.M., \& Mason M. J. (2004). The reflexive relationship between consumer behavior and adaptive coping. Journal of Consumer Research, 31(9), 441-454.

Rogers, E. M. (1995). Diffusion of innovations (4th. ed.). New York: Free Press.

Schein, E. H. (1987). Process consultation (2nd. ed. Vol. 1). Reading, MA: Addison-Wesley.

Schein, E. H. (1992). Organizational culture and leadership (2nd ed.). San Francisco: Jossey-Bass.

Seligman, M. E. P. (2002). Authentic happiness: Using the new positive psychology to realize your potential for lasting fulfillment. New York: Free Press.

Sillince, J. A. A. (1999). The role of political language forms and language coherence in the organizational change process. Organization Studies (Walter de Gruyter GmbH \& Co. KG.), 20(3), 485-518.

Slater, S. F., \& Narver, J. C. (1998). Customer-led and market-oriented: Let's not confuse the two. Strategic Management Journal, 19(10), 1001-1006.

Slater, S. F., \& Narver, J. C. (1999). Market-oriented is more than being customer-led. Strategic Management Journal, 20(12), 1165-1168.

Somech, A., Desivilya, H. S., \& Lidogoster, H. (2009). Team conflict management and team effectiveness: the effects of task interdependence and team identification. Journal of Organizational Behavior, 30(3), 359-378.

Strauss, A., \& Corbin, J. (1998). Basics of qualitative research: Grounded theory, procedures and techniques. Newbury Park, CA: Sage

Yin, R. K. (1994). Case study research : design and methods. (2nd ed.). Thousand Oaks : Sage Publications 
Table 1.

\begin{tabular}{|c|c|c|c|c|c|}
\hline \multicolumn{6}{|c|}{ Interview Samples } \\
\hline $\begin{array}{c}\text { Name } \\
\text { (Pseudonym) }\end{array}$ & Position & Current Job Responsibility & $\begin{array}{l}\text { Years of } \\
\text { Tenure }\end{array}$ & $\begin{array}{c}\text { Length of } \\
\text { interviews } \\
\text { (hours) }\end{array}$ & $\begin{array}{l}\text { Number of } \\
\text { interviews }\end{array}$ \\
\hline Mark & Founder & Strategic decision making & 11 & 2 & 1 \\
\hline John & CEO & $\begin{array}{c}\text { Company's operation and strategic } \\
\text { decision making }\end{array}$ & 11 & 5 & 2 \\
\hline Marry & General Manager & $\begin{array}{l}\text { Price setting, marketing and } \\
\text { customer service }\end{array}$ & 6 & 4 & 2 \\
\hline Allen & Consultants & $\begin{array}{l}\text { Locate operation problems and } \\
\text { propose improvements }\end{array}$ & 2 & 5 & 2 \\
\hline Chris & R\&D Manager & $\begin{array}{c}\text { Company's research and } \\
\text { development }\end{array}$ & 6 & 4 & 1 \\
\hline Anny & Vice General Manager & In charge of operations & 7 & 3 & 1 \\
\hline Mike & Marketing Officer & Design marketing campaign & 1 & 2 & 1 \\
\hline Nancy & HR Senior Specialist & $\begin{array}{l}\text { Training programs, orientation, } \\
\text { activities' planning }\end{array}$ & 1 & 1 & 1 \\
\hline Julia & Sales Manager & $\begin{array}{l}\text { Customer service and revenue } \\
\text { generation }\end{array}$ & 5 & 3 & 1 \\
\hline
\end{tabular}




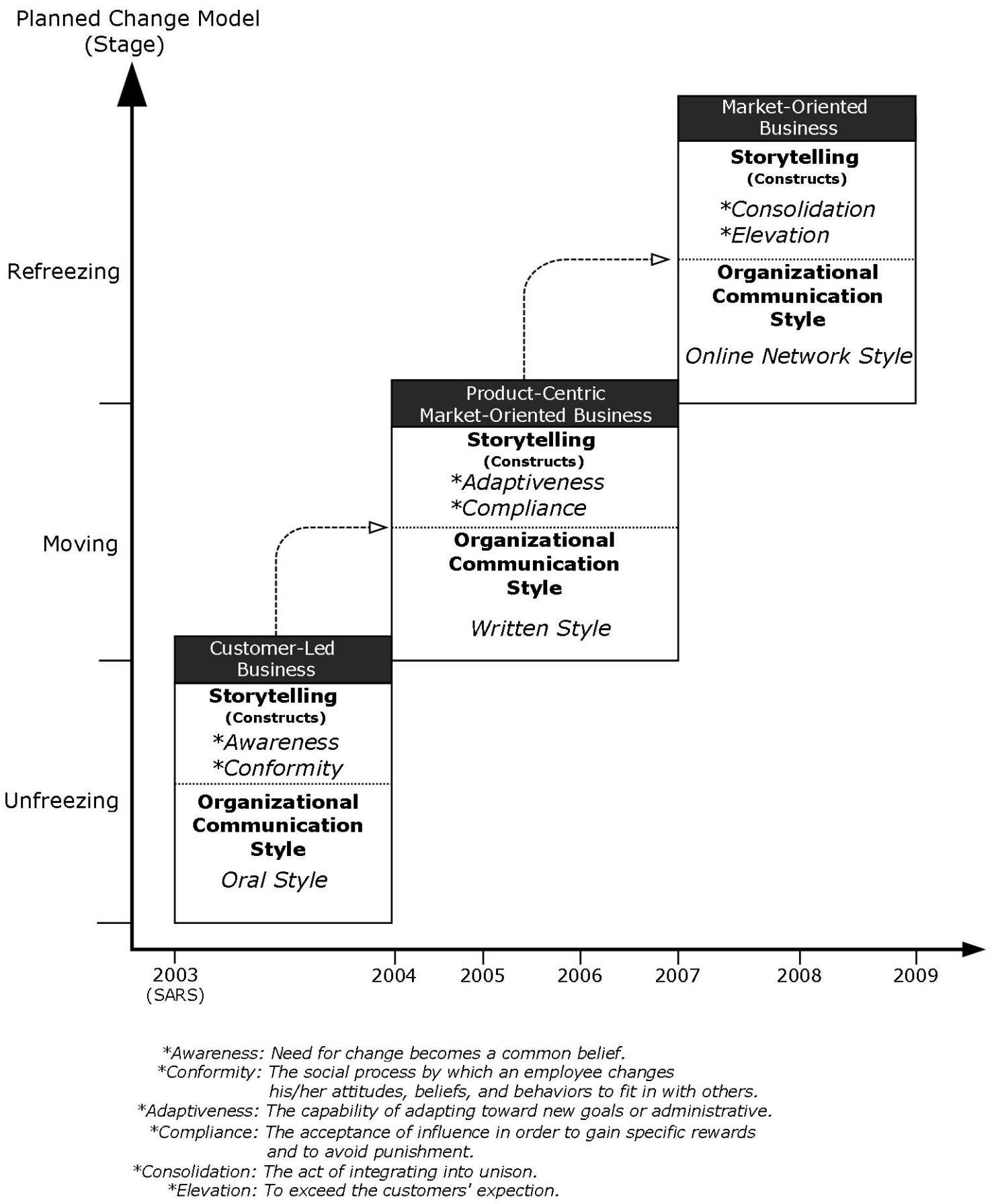

Figure 1. The three stages of cultural transformation 